\title{
Revolutionary Martyrs Former Residence Display Design Based on
}

\section{Augmented Reality}

\author{
Jia Rongyu \\ Communication\&Media College
}

ShanDong, 250200

\begin{abstract}
Revolutionary martyr's former residence is a special kind of cultural carrier, and is of high cultural value, education value and artistic value, but at present most of the former residence display form is single, and is lack of local characteristics and personality, which greatly affects the revolutionary martyr's residence propaganda and cultural influence. With the rapid development of science and technology, digital technology are fully used in modern display design art, gradually applied of modern science and technology in the design of revolutionary martyr's former residence cultural relics show becomes inevitable. This article will take China's revolutionary martyr's display of cultural relics form single status as a breakthrough point, argues that in the current information age, we must attach great importance to the corresponding requirements of the experience of the audience, combine residence of revolutionary martyrs display design with new augmented reality, change the traditional way of display, rich display content and display means, make home display design to keep pace with The Times, strengthen the residence time, innovation and artistic quality, improve the audience interest in residence of revolutionary martyrs, and better promote and protect the revolutionary martyr's former residence.
\end{abstract}

\section{Keywords: Revolutionary martyr's former residence; Augmented reality; Display art design}

With history changes, revolutionary martyr's former residence has become an important part of the history and culture, which has profound cultural value and artistic value, and is bearing the weight of patriotic education. In recent years, our country in order to enhance national cohesion and cultural soft power, carries forward revolutionary tradition, vigorously carries forward the red culture, party and state leaders repeatedly stressed that revolutionary martyr's former residence, revolutionary tradition resources belong to the precious spiritual wealth of our party and these red tourist attractions are a constant learning often with new and vivid classes, which contain rich nourishing of moral and political wisdom. Revolutionary martyr's former residence, compared with advanced museum display design, the vast majority residence of revolutionary martyrs is in relatively small size. In terms of facilities, technology, personnel and exhibits, they are at a disadvantage. Display artifacts appear extremely simple, and lack of local characteristics and personality. Display tends to be in the form of glass + card + name of the exhibits, using a simple graphic and in-kind listed martyr's life and less innovative and artistic. Whether exhibits extensibility, display form, or the means of display, etc., have been far behind the other kinds of display design. Although revolutionary martyrs' residences are free open to people, but by the impact of these factors, they are lack of visitors, and have not given full play to its role in traditional red culture. Based on the audience demand angle and informationization background, this paper analyzes the current residence of revolutionary martyrs display design problems and deficiencies, by showing forms and means of the effective combination of modern science and technology, explore measures to improve display design art of revolutionary martyrs residence.

\section{THE STATUS QUO OF THE CURRENT RESIDENCE OF THE REVOLUTIONARY MARTYRS RELICS DISPLAY}

From the perspective of the reality of our country revolutionary martyrs residence, widespread less financial investment, less personnel, and many other issues, less staff salary, low motivation, limited by 
the level of profession, cause long window display, the single display in the form of exhibits. For example, residence of anti-Japanese hero Ma Yaonan in Zibo Zhou village of north town north flourishing village, not only the residence is of old buildings and cultural relics show mainly is storefront window wall walk way, heroic story of the resistance war against Japan and the life are hanged in metope, the form of panel display is single, which is only maintained and managed by martyrs later generations. Many revolutionary martyrs' residences established visit pattern is through the glass, according to language tour guides, tour according to the direction of a visit. The residence artificial guide enthusiasm is generally low or no tour guide, while introduce exhibits, not reflect the deep connotation, the audience in a single mode can't have in-depth and selective visit at all. Lost interaction and one-way relationship between the audience and the residence is, and there is no way for audience with the help of revolutionary martyr's display exhibits to immerse into war environment, and to experience war period in Chinese history. Many martyrs' former residences have rich exhibits, but no show display design, which greatly weakens martyr's former residence spreading function of red culture. Some characteristics of martyr's former residences are not bright, exhibits quantity is less, and there is a certain historical research value, but with low artistic value. These martyr's former residence display design requirements for the exhibits will be higher. Luotian revolutionary martyr XiaoFang residence, for example, has long been actively exploring how to use unique angle of view and means to show the martyr's life, but although with elaborate display content, with a single display form influence, that is the static display, visitors are simply unable to imagine martyrs' living conditions at that time. Although Xiaofang martyr's residence cannot represent full display of the art status of revolutionary martyr's residences, but from a certain degree and angle, it illustrates the problem, that is the residence of the revolutionary martyrs show collections are more of a lack of interaction with the audience, and the showing form is one-way, and does not pay attention to build audience revolutionary martyr's presence sense.

\section{THE ENHANCED REALITY TECHNOLOGY CAN PROPERLY SOLVE LACK OF INTERACTIVE EXPERIENCE, AND SINGLE DISPLAY MEANS PROBLEMS IN REVOLUTION'S FORMER RESIDENCE}

As the change of time background, visitors to the revolutionary martyrs' residences experience requirements will change accordingly. When the revolution's former residence display exhibits focus on cultural relics with no full consideration of keeping pace with The Times demand, it leads to former residence carrying forward cultural heritage history effect failure. Based on the current information background, people access to information channels and lifestyle under the condition of the continuous development of information technology has huge changes. People make use of the internet terminal can get information and knowledge that they can't imagine the speed and the number of access to information. Under the impact of network knowledge dissemination, revolutionary martyr's former residence is surely worth a try and exploration direction which is to change the single form entity actively, with the aid of computer virtual technology and experience in the simulation of Internet technology, so that visitors get unforgettable information and deep impression.

Under the condition of rapid development of information technology, human society has stepped into digital age, an important trend in the development of technology is more efficient, fast, centralized information flows. From the current long term effect of the development of revolutionary martyr's former residence, residence development's inevitable trend is network, digital, intelligent and integrated. Analysis from the angle of design and exhibition display mode should have more design and diversity. According to real martyr's digital display characteristics, summarize the new direction for 
exhibition space expansion. A wonderful example of this in the current is augmented reality. Augmented reality based on virtual reality technology development, belongs to a new study range. As early as in 2001, Greece government designed and developed sun digital enhancement Archeoguide system which can reproduce the temple ruins of ancient Greece through the cooperation with scientific research institutions; University of Geneva MIRALAB laboratory received extremely outstanding research achievement with digital enhancement to reconstruct the ancient characters. The earliest augmented reality system platforms are desktop workstations or computers, fusion display device is perspective type helmet display. With the rapid development of network technology and mobile computing devices, more widespread application and research on augmented reality and virtual reality technology are used in network and various mobile devices.

Augmented reality can effectively fuse virtual to real, make experience the real environment to enhance perception, and visitors in the process of contact with the virtual world, are not cut the real world link. This interaction way can more fit people cognitive demands. It is common to apply image recognition based augmented reality in display design, revolutionary martyr's residence digital display application of augmented reality of cultural relics for the depth of the exhibition space to expand, with the aid of computer technology for revolutionary martyrs information visualization and reality, superposition, complementary virtual content and realistic environment, and provide a full range of exhibits information to tourists, and effectively improve visitors' digital browse revolutionary martyrs deeds, life experience and interactivity.

\section{EXHIBITION DESIGN ART OUTLOOK OF REVOLUTIONARY MARTYRS RESIDENCE BASED ON}

\section{AUGMENTED REALITY TECHNOLOGY}

Specifically, augmented reality is with the aid of technology simulation, within the scope of a certain space of time, implement superposition, and the difficult information of experiencing the real world before can be perceived in the real world. In revolutionary martyr's cultural relics display design process, the combination of virtual and actual, dynamic and static combination, real-time interaction approach can not only bring tourists new sensory experience, but also be able to greatly expand the revolutionary martyr's expression of time and space. Revolutionary martyr's display has contradictions as cultural relics and tourist demand, disproportionate era technology development. The inevitable development direction of former residence cultural relics in recent years on display is to be innovative, keeps pace with The Times, introduce new technology and modern way of display. Based on such conditions, a concern appears at the cost of the use of technical means, which can ascend the level of cultural relics, and not a point. Revolutionary martyr's former residences carry forward traditional culture. Based on modern technology, before formulating the corresponding strategies, red cultural relics display design must be clear to relevant national requirements. State administration of cultural heritage in 2012 formulated The Opinions on Strengthening Work Units of Cultural Relics on Display and Exhibition, which pointed out in the exhibition of cultural relics, must make scientific varieties prominent, so that the exhibition on display are stories, opinions and rich artistic conception, and avoid no high-quality goods exhibition values; Promote planning ability in tourist guide principle such as exhibition, strengthening planning, display with organic combination of ornament, interest, and information, and enhance the appeal and exhibition display; Specify design and production, scientifically use the existed higher artistic level auxiliary exhibits and electrical, optical and other modern technology. According to the above description, countries are actively advocating frugality, purposeful and conscious modern means of science and technology in the application of display design 
residence of revolutionary martyrs to make the level and ability of display exhibition effectively improved.

Future era of revolutionary martyr's residence display, as a result of the involvement of science and technology, will have particularly large display form changes, which closely relates to new technology and the development trend of information society. Revolutionary martyr's residence display development mainstream is for space, modernization and digital direction. Enhanced technology can effectively improve the exhibits and the interaction between the audiences. In recent five years, the current development of virtual technology is the application of augmented reality, especially widespread application in national revolutionary martyr's residence display design art. Experts and scholars of Beijing Institute of Technology mentioned to base on key frames matching tracking augmented reality registration algorithm to recreate digital historical building. At the same time, with the corresponding method of random numbers, the problem of feature point matching can be gradually transformed to feature pattern classification problems, image matching wide baseline characteristics problem can be solved. Through the algorithm, build mobile augmented reality system based on video fluoroscopy type helmet display. From the related research results, this method has robustness and real-time characteristics, and is suitable for outdoor track registration. Although it can enhance the experience results, there is a high cost and high maintenance requirements. Most revolutionary martyrs' residences are lack of manpower and money, and for a long time have no way to popularize. Gradually risen small handheld mobile devices still can use mobile augmented reality system. Now quite a number of mainstream handheld mobile devices will have built-in cameras above millions of pixels, and integrate infrared interface network equipment such as wireless local area network, Bluetooth wireless interface, and high-speed wireless communication. And in the process of designing software, the residence of the revolutionary martyrs' relics experience is ascended step by step.

Under the background of current digital virtual technology, with the development of display design art, modern means and forms of display will be shown to more use of residence of revolutionary martyrs. Reasonable use of expression form of contemporary exhibition design, use of augmented reality technology and new materials, the former residence display design expression means change from pure exhibits to sound design with painting combination, and the comprehensive display design art activity to strengthen the residence art and education, and fully carry forward the traditional culture, education value, and better protect revolutionary martyrs former residences.

\section{REFERENCE}

[1] Chen Jing, Wang Yongtian, Lin Jingdun, Guo Junwei guo, Liu Wei, Ding Gangyi. The old Summer Palace landscape digital recreation based on augmented reality [J]. Journal of System Simulation. $2010(02): 32-35$

[2] Zhang Min, Fu Yijin. The technology era show art - based on the theory study of expo exhibition space [J]. Hundreds of Arts. 2010 (5) : 2-5

[3] Zhang Min, Zhu Qing, Zhang Chao. Exhibition center, or video center?-The pitfalls of story worship show art need to get out [J]. Journal of Art. $2011(01): 73-76$

[4] Wang Xiaoyu. Creative design of characteristics museum- inductive of London old operating room museum situation design [J]. 2012 (4) : $84-85$

[5] Wang Bo. Shallow concern on the application of virtual reality technology in modern media art [J]. Journal of Chifeng Institute (Science Education Edition), 2011 (01) : 41-43 